OPEN ACCESS

Edited by:

Gillian Hue,

Emory University, United States

Reviewed by:

Kristen Frenzel,

Emory University, United States

Cindy Achat-Mendes,

Georgia Gwinnett College,

United States

*Correspondence:

B. Daniel Pierce

bpierce@richmond.edu

Specialty section:

This article was submitted to

Science and Environmental

Communication,

a section of the journal

Frontiers in Communication

Received: 27 June 2021

Accepted: 20 October 2021

Published: 08 November 2021

Citation:

Pierce BD (2021) Translating Monastic

Lessons to Teaching

Undergraduate Biology.

Front. Commun. 6:731497.

doi: $10.3389 /$ fcomm.2021.731497

\section{Translating Monastic Lessons to Teaching Undergraduate Biology}

\section{B. Daniel Pierce*}

Department of Biology, University of Richmond, Richmond, VA, United States

My participation in the Emory Tibet Science Initiative (ETSI) has afforded me considerable means to enrich my teaching at the undergraduate level. Here, I discuss how I translated lessons learned from working with Tibetan Monks to teaching in a primarily undergraduate institution, including: 1) introducing each course with a challenge to the assumptions made as "Western scientists" 2) using the unique monastic pedagogy of debate to facilitate classroom scholarship, and 3) embracing compassion as a central tenet to engage and empower student learning, which has become the cornerstone of my teaching philosophy. In addition, I brought undergraduates with me to participate in ETSI, and the experience had a profound effect on their educational and career paths. These experiences with the Tibetan monks transformed my teaching and continue to inform how I approach undergraduate education.

Keywords: tibetan monks, primarily undergraduate institution, introductory biology course, inclusive pedagogy, ETSI, tibetan debating

\section{INTRODUCTION}

At first glance, my teaching at the University of Richmond (UR), a primarily undergraduate institution (PUI), and the teaching I did with ETSI at Sera Jey Monastery in Bangalore, India, appear to have stark differences (ETSI, 2021; Gray \& Eisen, 2019). In a typical UR class, I teach in English to about 18 students at a time who are from the ages of 17-21, all sitting at desks or lab benches using a variety of student-centered group work activities with inquiry-based labs (Figure 1A). At the monastery, I taught through an interpreter to 75-80 Tibetan monks of various ages, all sitting crosslegged on the floor in their maroon robes, while I wrote on a portable white board or presented slides and videos projected on the wall of a large room (Gray \& Eisen, 2019). While these differences are pronounced, what I came to realize as I alternated between the two situations over a 6-year period is how similar these experiences actually are-and how they provided concrete lessons that I ultimately translated from the monastery to my classroom at UR.

For me, teaching science is about asking questions. Posing questions and exploring answers with my students is fundamental to my roles as a science educator. And in turn, the spark that comes when students ask questions that show that they have gained a new insight about life is a very meaningful moment for me and for them. In many ways, teaching and learning is the same across vastly different contexts, and my experience with the monastics has led me to explore how this work informs how I teach biology to undergraduates.

\section{"What Is Life?"}

When I first went to India to teach and learn with the Tibetan monks in the summer of 2014, I did not know what to expect, and leaned heavily on my co-teacher who had previous teaching experience there. The prompt we used to launch our first session with the monks was "What is life?" and from there we moved to "What makes something alive? What makes something 'not alive'?" As we began 


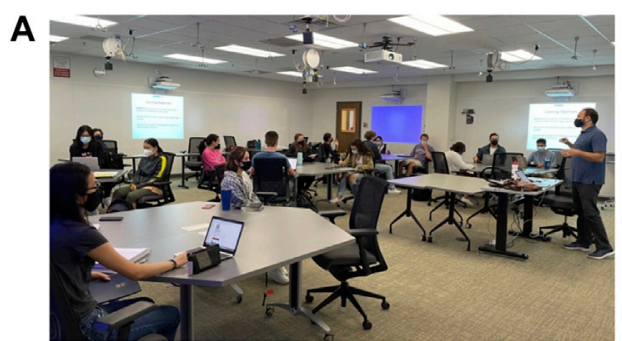

B

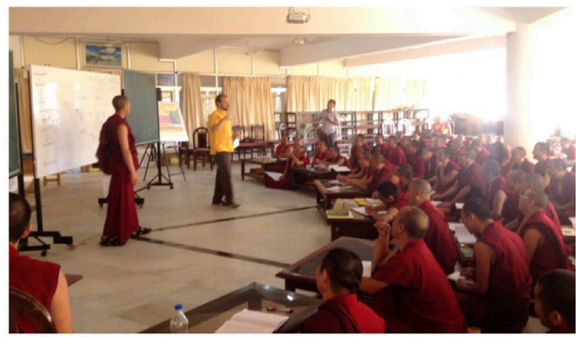

C

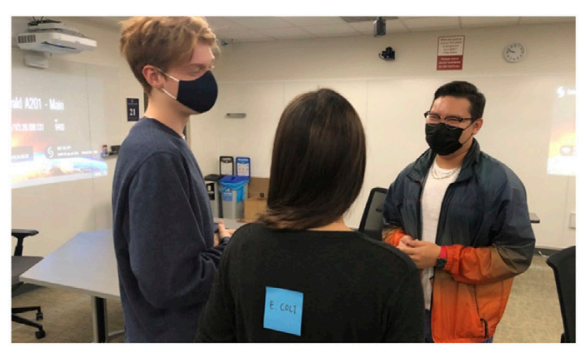

D

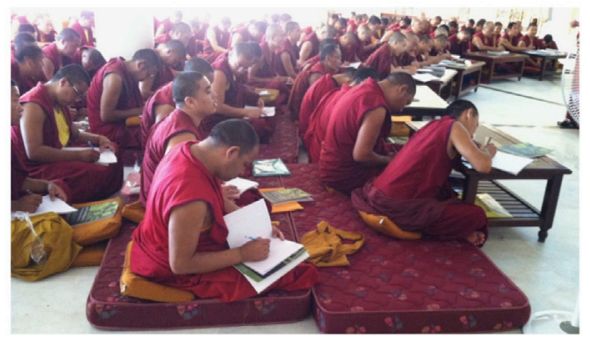

E

$\mathbf{F}$

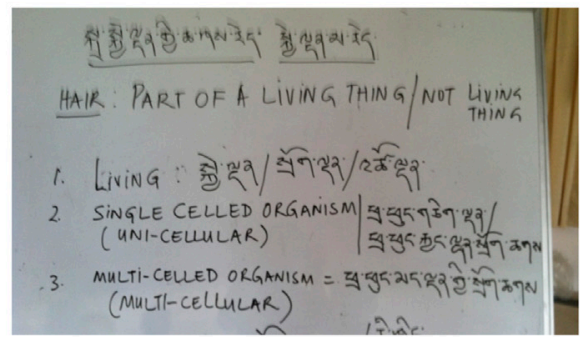

G
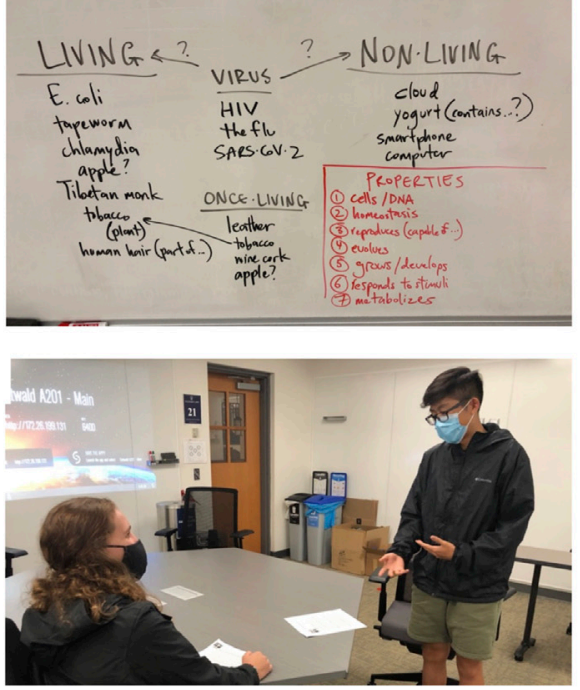

H

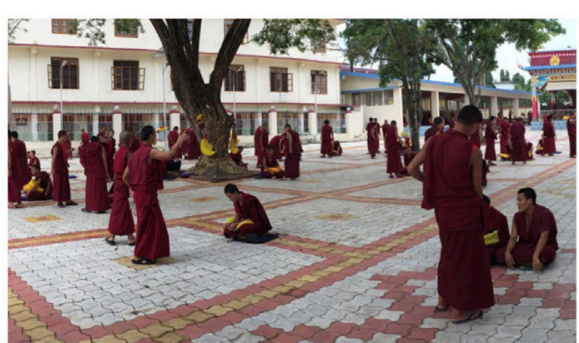

FIGURE 1 | Comparing the undergraduate PUI teaching experience to teaching monks. A typical classroom at the University of Richmond (A) compared with a typical classroom at the Sera Jey monastery in Bangalore, India (B). Smaller classroom sizes allow for active participation in determining "what is life" (C, E) but similar learning objectives can be achieved through large lecture techniques (D, F). Debate can be incorporated into the undergraduate classroom (G) and is essential to monastic learning $\mathbf{( H )}$. Written informed consent was obtained from the individuals for the publication of identifiable images.

to think about these topics, I remembered a book my father gave me when I was in high school: What is Life? by Erwin Schrodinger ("Schrodinger, Erwin. What Is Life? New York: The Macmillan Schrodinger, 1945.91 p. \$1.75,” 1945). Just as Schrodinger's book sparked my interest in how we approach fundamental biological questions, these questions inspired remarkable discussions at the monastery. Even though I had prepared to be sensitive to cultural differences, the initial questions from the monks flustered me a bit and I found myself in a position of defending Western biological "settled science" that we often assume undergraduates know. I was able to recover my footing by explaining how scientific theories are built. As we discussed the scientific method by which experiments are controlled, data are analyzed, and theories are built, some of the intellectual tension was relieved.

An example of this occurred during one of the early "Question and Answer" periods, when a monk questioned my use of chickens as an example about how genetic material is passed from parents to offspring. He assured me that he knew of a rooster that was able to produce eggs and that my claim that only hens lay eggs was incorrect. I was perplexed by this and immediately denied this possibility, which led to a conflict as he insisted that I was wrong-that he had seen a rooster lay eggs. After reflecting on this conversation that night, I decided to take a different tact the next day. I brought up the example again and asked, "How would a scientist prove that roosters can lay eggs?" 
Together we talked about how we would set up this experiment: What conditions would we keep the roosters in? How many roosters would we use? What would be our controls? Suddenly our topic was no longer arguing the "fact" of whether roosters can or cannot produce eggs, but we were exploring how science can lead to these "settled" theories.

By contrast to classes at a monastery, most scientific courses at the undergraduate level do not deal directly with potential epistemological conflicts. Students who take a first-year biology course at the University of Richmond or any Western university have been exposed to the definition of a living thing at some point in their middle and high school education-often through rote memorization and without an analysis of the topic in a deeper way. But, following from the teaching I have done at the monastery, I have found it more productive and engaging to start my undergraduate courses with a fundamental question like, "How do you know what a living thing is?" Such inquiries do two things: First, they force our students to immediately start questioning some of the dogma that can permeate biology education. Second, these initial challenges allow me to discuss concepts that are core to biological teaching and learning, such as hypothesis testing, repetition of experiments, and scientific communication.

\section{Characteristics of a Living Thing}

In the first biology class with either monks or undergraduates, I have slightly modified lessons with both groups of students to build to our definition of life. For the monastics, because it is a large group in a large space, I have each monk draw three living things and three non-living things (Figure 1D). Then, they compare answers with a partner and we draw a similar collection on the whiteboard. Though many monks have some experience with English, drawing pictures usually elicits a quicker response and quickly injects some humor into the classroom. This initial activity gets at some fundamental differences between "Western science" and the monastic texts: Is a plant a living thing? Is a mushroom a living thing? Is human hair a living thing? These basic questions immediately draw out differences between the Western understanding of life and the Tibetan Buddhist texts (Figure 1F). Usually there is no full agreement at the end of this discussion, but it allows us to begin characterizing what most of the "living things" have in common: grow/develop, reproduce (though not always), consume, move (though not always), etc. With this short activity, there is almost always a great energy in large room and the monks are eager to debate these topics further and learn more.

In the undergraduate classroom, we play an introductory game to build to the answer of our definition of life. First, I assemble a list of words on sticky notes and place one word on the back of each student. Then, students circulate through the class, asking each other yes or no questions to try and determine what word is on their back (Figure 1C). In addition to words that might come up in a first-year biology course ("mitochondria, E. coli"), I add words that were particularly difficult for the monastic scholars to place as living or non-living in order to spark discussion with the undergraduates once we assign these words to "living" or "non-living" categories (Table 1). Once everyone in the room has correctly guessed their word, together we group these words into the category of "living" or "non-living" (Figure 1E). While this initially seems like a trivial question to a college student, it provides an opportunity for early participation in the class and, invariably, success, which is an effective inclusive pedagogical practice (K. D. Tanner, 2013). I have used this introductory game for approximately 10 first-year classes with remarkable engagement and debate. As an undergraduate class, we then develop a list of "characteristics of living things" by looking at our table. This is where many collegiate textbooks begin as well.

In both groups, we now have our list of "characteristics of living things" and we track back to our original table of living versus non-living things to find the points of tension for clarification. For example, most monks and undergraduates will say that an apple is a non-living thing, but surely it contains cells. Also, when does a part of a living thing, such as a human hair, transition to something that is "non-living"? The question of individual living things versus a collective becomes paramount as well. How do we describe what happens when a flatworm is cut and becomes two flatworms biologically? How does this change when we understand the Buddhist view of a spirit that inhabits each living thing? These are rich subjects to mine for monks and undergraduates, with the definitions leading to excellent discussions.

After classifying the objects as "living" or "non-living" (often with a third category, "once lived") (see Table 1), we come to a consensus list for the characteristics of life. With some facilitation from me, the students develop a list of six to seven characteristics that are found early in an introductory biology textbook (For undergraduates, I specifically stop here and discuss viruses-we see how many of the characteristics a virus has and, depending on the consensus of the students' opinion about whether or not a virus is "alive", I try to argue in support of the opposite side using Socratic dialogue to support conceptual change (Fleming, 2018; Reich, 2003; K.; Tanner \& Allen, 2005). Through a question-andanswer period, both the monks and undergraduates develop a list of these characteristics on their own (see Figure 1E). The monks have the dogma of their religious texts and the students the dogma of current Western science beliefs, but both can be respectfully challenged through asking questions. I facilitate the students hashing out their rules for what living things are. The conversations that arise for undergraduates are "easy" in the sense that they all have been taught the dichotomy between nonliving versus living things from an early age. Being challenged early in an undergraduate career to really probing these dogmas help students appreciate the importance of interrogation. I connect this with the idea that science is a process, building theories, not laws, that should always be up for review and challenge.

\section{Tibetan Monastic Debate and the Undergraduate Classroom}

I have translated my experience with the monks to the undergraduate classroom through the use of Tibetan monastic debate to facilitate classroom scholarship. Debate is a fundamental part of the educational process in monastic 
TABLE 1 | Typical table generated through class discussion to designate objects as "living" or "non-living". To develop the following table, undergraduates were each given one word that they could not see and asked to guess the word using "yes or no" questions. The difficulty of placing certain items as "living" or "non-living" allows for an introduction to biological inquisition.

\begin{tabular}{|c|c|c|}
\hline Living & Once-Living & Non-Living \\
\hline E. coli & Apple (no seeds) & Apple seeds \\
\hline Chlamydia (obligate parasite) & Wooden Table & Metal Table \\
\hline Human hair (part of) & Human hair? & Smartphone \\
\hline Mitochondria (part of) & Cork & Computer (can Al become life?) \\
\hline Mistletoe (parasite) & Cocoa Powder & Cloud \\
\hline Monk & & Fire \\
\hline Yogurt (contains) & & Virus? \\
\hline Virus? & & \\
\hline
\end{tabular}

communities (Vugt et al., 2020). These debates involve dozens of monks spread out in a large, open air theater, with one standing monk "educating" and a sitting monk "receiving the education" (Dreyfus, 2003; Perdue, 2014). The educating monk simultaneously does three things: takes a step, hits one hand into the other, and delivers a message to the receiving monk. Monastic debate can be used for a variety of educational purposes, including a deeper understanding of religious texts. The receiving monk listens and may or may not respond to the message, but usually do (for a sample transcript of a monastic debate, please see (Vugt et al., 2020). The educating monk may respond back to the receiving monk, but the discussion is specifically related to the particular lesson that is being delivered.

When I ask undergraduates to describe Western debates, especially in election years, they rarely have anything positive to say. The occasional student who has participated in debate teams may have more positive associations with debate, but they tend to agree that understanding and learning do not seem to be central to the "purpose" of the debate. Though many types of Western debate certainly have their merit, I would argue that, for the purpose of learning and instilling academic rigor, Tibetan style debate is really what we hope to inspire in our students. When teaching in the monastic style, I usually assign the debate in one class period and conduct the debate in the next, directing students to develop deeper understandings of the material rather than trying to pick apart opposing views. The student leading the debates are instructed to develop several main points to deliver, and the student receiving can ask clarifying questions. While I have tended to use topics that can be "debated" in the way Western students understand debate, it could be possible to use monastic debate to practice understanding biological concepts where students would use this technique to internalize these concepts.

After discussions of the debates with several monks, I have used their explanation of the purpose of debate to set up this pursuit of knowledge in the undergraduate classroom. Specifically, debates are used by the monks to probe for understanding, develop critical thinking, make connections between topics, and build compassion (Perdue, 2014; Vugt et al., 2019, 2020). Through rigorous study, monastics prepare for these debates to achieve the learning goals. When we enact debate in my courses, students choose a position to debate and present it to partners or the class (Figure 1G). We listen and respond to their point while taking care to focus specifically on the content. There are no winners in these debates, only knowledge gained and new perspectives considered. Teaching through the use of this style debate has allowed me to introduce potentially challenging subject manner in a way where students are not trying to win or score points. For instance, students in my introductory Synthetic Biology course have debated editing human embryos. While this subject was until recently mostly science fiction, CRISPR and other DNA editing techniques have made this work feasible. Through the use of Tibetan monasticstyle debating, students have discussed the specifications to which this type of technology should be applied. In addition to this topic, I have facilitated debates on topics from "Should scientists be allowed to "create" synthetic life?" to "What type of grants should the NIH fund?". Students self-report that they found these debates engaging and enjoyed the opportunity to learn in this new way. Additionally, these debates would provide an excellent opportunity to explore how social justice issues intersect with biology, such as the ethics of informed consent and approaches to address environmental injustice stemming from racism.

\section{Teaching With Compassion}

Working with the monks has given me new appreciation for the value of compassion and led me to fully integrate it into the classroom in order to engage and empower student learning. This idea-to teach while caring - has become the cornerstone of my teaching philosophy. Specifically, I have incorporated community-building techniques into my teaching as a manifestation of this compassion. The monks live an existence that seeks out compassion in a community that reaffirms this goal. While there are times and junctures in our lives where being compassionate is difficult, if not impossible, I have made it an explicit goal of my courses to demonstrate and cultivate compassion. Though many of these instances occur naturally when I am teaching or working with students, I also intentionally add moments where we address questions of the social responsibility of biologists and consider the people involved in current and historical biological discoveries in order to build community through the discussion of challenging topics.

While it might seeem difficult to include compassion into every topic or lesson plan, finding moments to build classroom community is an effective aspect of inclusive teaching (K. D. Tanner, 2013), and compassion can lead to these moments. For example, I teach a Cancer Biology course where I build the course historically, bringing in prevalent theories from the past. We then 
discuss how these theories were supported or rejected. One of the characters in this history is William Halsted, who developed the radical mastectomy as an attempt to prevent the deaths of women to metastasizing breast cancer. Through the use of compassion, we can analyze the cultural context of the women who had this disease-what was the stigma around cancer at the end of the 19th century? were they empowered to make choices? what were their lives like? - and attempt to understand their feelings as they went to Halsted for the operation. Additionally, we can endeavor, though more difficult, to have compassion for Halsted, who was addicted to cocaine and by all appearances had a real desire to save lives, though his methods were truly appalling in retrospect. Teaching in this way provides multiple places where students can connect with difficult subjects, aiding in the learning process and creating classroom discussion topics that build community.

\section{Undergraduate Interaction}

In addition to the effect the monastery has had on me and my own teaching, exposure to learning in this context has also had a direct impact on a pair of my students. In 2019 I was able to bring two students to the monastery from UR through the EnCompass Program (https://international.richmond.edu/ study-abroad/short-term/encompass/). This program is designed to help students access an undergraduate abroad experience who might not otherwise do so. I chose these students based on their interest in connecting with the monks, and they interacted with the monks as Teaching Assistants for our science classes there, conducted their own interviews with the monks, and continually reflected on their experience (https://blog.richmond.edu/encompassindia/). Each reported an increase in their engagement with science as a result of this experience, and this engagement has been wellcharacterized in these experiential learning opportunities (Daniel \& Mishra, 2017; Achat-Mendes et al., 2020; Long et al., 2020). As one writes, "when I returned back to campus for classes, I found myself more engaged with my biology courses and having more personal interest in learning."

The UR students developed a strong affiliation with Buddhism and the monks, and they continued to harbor these feelings months later. One student describes his experience: "As a young American, I see clearly that many people my age naturally agonize over where they will be and what they will be doing in their future. In my view, herein lies the immense value of the EnCompass programs and others like them-they are able to provide some much-needed perspective for young people who face many paths forward in a confusing and overwhelming world. Whether I become a financial analyst, professor of philosophy, a monk or

\section{REFERENCES}

Achat-Mendes, C., Anfuso, C., Johnson, C., and Shepler, B. (2020). Learning, Leaders, and STEM skills: Adaptation of the supplemental instruction model to improve STEM education and build transferable skills in undergraduate courses and beyond. J. STEM Educ. Innovation Res. 20, 2. something entirely different, I believe I am able to make a more informed, comfortable, and confident decision because of my experience."

Based on the examples set by the monks, each of us built mindfulness practices that endure in our lives to this day. By experiencing the Sera Jey monastery with these students, I reexperienced my first time there and discovered connections between the monastics and our current generation of college students, including the universality of community, inquiry, and compassion.

\section{DISCUSSION}

My experience teaching and working with my monastic students is one of the most meaningful of my career. My concept of compassion has transformed from a piece to add to my courses to an organizing principle of my professional life. Working with the monks has led me to a place where I embrace and nurture the educational light inside of each of my students. Many of our undergraduate students are fueled by a sense of justice and a desire to affect change, and inspiring inquiry that is centered in compassion is a powerful way to help these students build their path forward.

\section{DATA AVAILABILITY STATEMENT}

The original contributions presented in the study are included in the article/Supplementary Material, further inquiries can be directed to the corresponding author.

\section{AUTHOR CONTRIBUTIONS}

DP developed this article based on his experience in India with ETSI and at the University of Richmond.

\section{FUNDING}

DP is a member of the biology faculty at UR and his trips to India to work with the Tibetan monks was funded by ETSI and Emory University. Undergraduate students were funded through the EnCompass Program at UR, which thanks to generous supporters offers faculty-led travel for students otherwise unlikely to travel abroad.

Daniel, K. L., and Mishra, C. (2017). Student Outcomes from Participating in an International STEM Service-Learning Course. SAGE Open 7 (1), 215824401769715. doi:10.1177/2158244017697155

Dreyfus, G. (2003). The sound of two hands clapping: the education of a Tibetan Buddhist monk. California: University of California Press.

ETSI (2021). September 17 Emory Tibet Science Initiative. https://tibet. emory.edu/. 
Fleming, C. J. (2018). Reflections on academic lives: Identities, struggles, and triumphs in graduate school and beyond. J. Public Aff. Edu. 24 (3), 420-422. doi:10.1080/15236803.2018.1460190

Gray, K. M., and Eisen, A. (2019). The Emory-Tibet Science Initiative: Rethinking Cross-Cultural Science and Teaching. J. Microbiol. Biol. Educ. 20 (1), 30. doi:10.1128/jmbe.v20i1.1618

Perdue, D. E. (2014). The course in Buddhist reasoning and debate: an Asian approach to analytical thinking drawn from Indian and Tibetan sources. Colorado: Shambala Publications.

Reich, R. (2003). The Socratic Method: What it is and How to Use it in the Classroom, 13. Stanford: Center for Teaching and Learning (CTL), Stanford University. https://tomprof.stanford.edu/posting/810.1.

Schrodinger, E. (1945). Schrodinger, Erwin. What is life? New York: The Macmillan Company, 1945. 91 p. \$1.75 New York: Sci. Ed. Sci. Edu. 29 (4), 220. doi:10.1002/sce.3730290430

Tanner, K., and Allen, D. (2005). Approaches to Biology Teaching and Learning: Understanding the Wrong Answers-Teaching toward Conceptual Change. Cbe 4 (2), 112-117. doi:10.1187/cbe.05-02-0068

Tanner, K. D. (2013). Structure Matters: Twenty-One Teaching Strategies to Promote Student Engagement and Cultivate Classroom Equity. Lse 12 (3), 322-331. doi:10.1187/cbe.13-06-0115

Tien Long, N., Thi Hoang Yen, N., and Van Hanh, N. (2020). The Role of Experiential Learning and Engineering Design Process in K-12 Stem Education. Int. J. Edu. Pract. 8 (4), 720-732. doi:10.18488/ journal.61.2020.84.720.732 van Vugt, M. K., Moye, A., Pollock, J., Johnson, B., Bonn-Miller, M. O., Gyatso, K., et al. (2019). Tibetan Buddhist monastic debate: Psychological and neuroscientific analysis of a reasoning-based analytical meditation practice. Prog. Brain Res. 244, 233-253. doi:10.1016/bs.pbr.2018.10.018

van Vugt, M. K., Pollock, J., Johnson, B., Gyatso, K., Norbu, N., Lodroe, T., et al. (2020). Inter-brain Synchronization in the Practice of Tibetan Monastic Debate. Mindfulness 11 (5), 1105-1119. doi:10.1007/s12671-020-01338-1

Conflict of Interest: The author declares that the research was conducted in the absence of any commercial or financial relationships that could be construed as a potential conflict of interest.

Publisher's Note: All claims expressed in this article are solely those of the authors and do not necessarily represent those of their affiliated organizations, or those of the publisher, the editors and the reviewers. Any product that may be evaluated in this article, or claim that may be made by its manufacturer, is not guaranteed or endorsed by the publisher.

Copyright $\odot 2021$ Pierce. This is an open-access article distributed under the terms of the Creative Commons Attribution License (CC BY). The use, distribution or reproduction in other forums is permitted, provided the original author(s) and the copyright owner(s) are credited and that the original publication in this journal is cited, in accordance with accepted academic practice. No use, distribution or reproduction is permitted which does not comply with these terms. 